\title{
The Influence of the Support Structure on Residual Stress and Distortion in SLM Inconel 718 Parts
}

\author{
TATIANA MISHUROVA, SANDRA CABEZA, TOBIAS THIEDE, \\ NARESH NADAMMAL, ARNE KROMM, MANUELA KLAUS, \\ CHRISTOPH GENZEL, CHRISTOPH HABERLAND, and GIOVANNI BRUNO
}

The effect of support structure and of removal from the base plate on the residual stress state in selective laser melted IN718 parts was studied by means of synchrotron X-ray diffraction. The residual stresses in subsurface region of two elongated prisms in as-built condition and after removal from the base plate were determined. One sample was directly built on a base plate and another one on a support structure. Also, the distortion on the top surface due to stress release was measured by contact profilometry. High tensile residual stress values were found, with pronounced stress gradient along the hatching direction. In the sample on support, stress redistribution took place after removal from the base plate, as opposed to simple stress relaxation for the sample without support. The sample on support structure showed larger distortion compared to sample without support. We conclude that the use of a support decreases stress values but stress-relieving heat treatments are still needed.

https://doi.org/10.1007/s11661-018-4653-9

(C) The Minerals, Metals \& Materials Society and ASM International 2018

\section{INTRODUCTION}

SELECTIVE laser melting (SLM) is a powder-bed-based additive manufacturing (AM) technique which gives the possibility of producing near-net shape structures with complex geometry and good mechanical performance. ${ }^{[1]}$ The fabrication of comparable complex components with conventional manufacturing techniques needs more effort and creates much more wastes, if it is even possible. ${ }^{[2]}$ For the AM processes, however, powder characterization, the component tailored optimization of microstructure, mechanical properties and design, as well as process quality control need to be done at every step of manufacturing. ${ }^{[3,4]}$ Furthermore, due to

TATIANA MISHUROVA, TOBIAS THIEDE, NARESH NADAMMAL and ARNE KROMM are with the Bundesanstalt für Materialforschung und -prüfung (BAM), Unter den Eichen 87, 12205 Berlin, Germany. Contact e-mail: tatiana.mishurova@bam.de SANDRA CABEZA is with the Institut Laue-Langevin, 71 Avenue des Martyrs, 38000 Grenoble, France and also with the Bundesanstalt für Materialforschung und -prüfung (BAM). MANUELA KLAUS and CHRISTOPH GENZEL are with the Helmholtz-Zentrum Berlin für Materialien und Energie GmbH, Hahn-Meitner Platz 1, 14109 Berlin, Germany. CHRISTOPH HABERLAND is with the Siemens AG, Power and Gas, Huttenstrasse 12, 10553 Berlin, Germany. GIOVANNI BRUNO is with the Bundesanstalt für Materialforschung und -prüfung (BAM) and also with the Institute of Physics and Astronomy, University of Potsdam, Karl-Liebknecht-Str.24-25, 14476 Potsdam, Germany.

Manuscript submitted November 10, 2017.

Article published online May 10, 2018 the multi-layer deposition technique, complex residual stress (RS) fields typically are present in SLM parts.

The origin of RS has been identified as the high thermal gradients during SLM, and discussed in Reference 5. During the manufacturing process, the top layer expands, while the previous layers cool down. Extending this phenomenon to a multi-layer finally leads to large thermal gradients along the building direction. Therefore, delamination and cracks have been observed even during production. ${ }^{[6]}$ The stress-relieving heat treatment after production cannot solve the problem of the thermal cracks and distortion during manufacturing. Therefore, the problem needs prevention rather than cure: the scanning parameters and the scanning strategy need to be optimized. Thermal gradients are highly affected by manufacturing parameters. ${ }^{[7]}$ The influence of the scanning strategy on RS state has been reported in several studies. ${ }^{[5,8-11]}$ In the last work, the authors have discussed a decrease in RS by island scanning strategy, which consists of scanning small square-shaped areas.

A support structure can prevent cracking and compensate distortion due to high RS. Support structures are especially useful for overhanging features ${ }^{[4]}$ since they bear the weight of the part as well as compensate the distortion along the horizontal direction. Besides, a support structure facilitates heat dissipation, since a loose powder has very poor thermal conductivity. Also, it plays a role of additional material stock to the base plate for more precise part removal. In Reference 10, the influence of the support structure on cracking due to RS 
has been discussed, and it has been recommended that the support structure with more contact area to sample needs to be placed near the ends of the part, since the maximum residual stress has been observed there. Also RS analysis by X-ray diffraction in Reference 12 for Ti-6Al-4V parts has shown a reduction of stresses for a sample on support structure with respect to bulk samples. In contrast, for residual stress measured by hole drilling method in SLM AlSi10Mg, ${ }^{[13]}$ the sample without support has shown the lower stress values. Therefore, support structures impact the design and optimization of any SLM product ${ }^{[14,15]}$ and their effect strongly depends on material and geometry.

It is well established ${ }^{[9,16]}$ that the removal from base plate leads to RS-release that implies a distortion of the SLM parts. This distortion could be easily measured on the top surface of the part. In fact, distortion can be used as an inexpensive and fast assessment of the amount of RS in the part, ${ }^{[17,18]}$ as well as for quality assurance scopes. In comparison to bulk residual stress analysis by neutron diffraction, ${ }^{[19,20]}$ synchrotron radiation diffraction allows RS investigations in subsurface regions (up to $100 \mu \mathrm{m}$ depth).

In the present study, we combine surface distortion maps with subsurface RS fields obtained by energy dispersive synchrotron X-ray diffraction. ${ }^{[21]}$ We also investigate the influence of a support structure and of the removal from the base plate on residual stresses in Inconel 718 prism-shaped samples produced by SLM.

\section{EXPERIMENTAL}

The samples were manufactured by Siemens AG, Power and Gas Division, Berlin, Germany. The SLM fabrication was conducted on an EOS M290 machine. A powder of Inconel 718 produced by gas atomization was used for the fabrication. One sample was produced on a lattice support structure (Figure 1(a)) and another one directly on a base plate (Figure 1(b)). The design of the lattice supports was optimized to keep the part in place during manufacturing and to prevent its distortion and delamination from the support. The final design, as shown in Figure 1(a), is proprietary to Siemens. All process parameters during SLM were kept the same for both samples. The sample on support structure (S) had a nominal thickness of $1 \mathrm{~mm}$, while the bulk specimen (B) was $20 \mathrm{~mm}$ thick. The $\mathrm{S}$ sample is attached to the
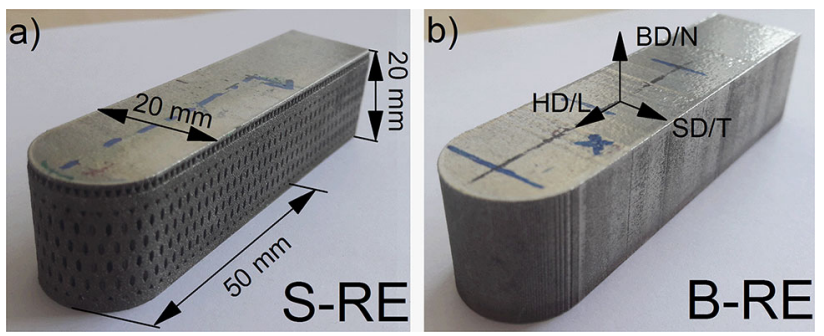

Fig. 1- Definition of sample coordinate system for specimen $(a)$ on support (S-RE), (b) bulk (B-RE). Size and coordinates are the same for both samples. support structure with a period (i.e., distance between two contact points) of around $2 \mathrm{~mm}$. The geometry of the manufactured specimen and coordinate system is given in Figure 1. Both samples were produced using the same set of parameters. Details cannot be disclosed as the parameters used are non-standard EOS parameters and proprietary to Siemens AG. Three up-skin layers were deposited for all specimens. The energy density for up-skin layers was 4 pct lower than for the bulk scanning strategy.

The samples were investigated in two conditions: as-built on the base plate $(\mathrm{AB})$ and in released condition (RE), removed from base plate by wire erosion. It should be mentioned that in the sample S-RE the support structure was not removed as the cut was performed close to the base plate to maintain as much support structure as possible (Figure 1(a)). Top surface distortion of samples in both conditions (AB and $\mathrm{RE}$ ) was measured with a tactile coordinate measuring machine (CMM, Werth Scope Check ${ }^{\circledR}$ S) using a ruby ball with a diameter of $3 \mathrm{~mm}$. CMM has an instrumental error in the range of $3 \mu \mathrm{m} .^{[22]}$

A bidirectional scanning stripe strategy was used for production with the hatching direction (HD) along the longer dimension (length) of the sample. The scanning direction (SD) defines the stripe scanning direction along the sample width. The building direction (BD), the directions HD and SD define together the three principal geometrical directions of the samples. Stress components (Figure 1(b)) along the principal geometrical directions were named longitudinal (L, along HD), transversal ( $\mathrm{T}$, along $\mathrm{SD}$ ), and normal ( $\mathrm{N}$, along $\mathrm{BD}$ ).

Small specimens of $10 \mathrm{~mm}$ length were wire-cut using electro-discharge machining (EDM) method from one end of the specimen for the detailed microscopic analysis. This sample cut was proven by laboratory X-ray diffraction (not reported) not to alter the RS state in the region far from the cut. Since the thickness of the $\mathrm{S}$ sample was around $1 \mathrm{~mm}$ only, few portions from the support structure were also included during cutting. Metallographic specimen preparation was started by rough grinding from the emery papers of grit P120, continued with P320, P600 and ended by using P1200. This was followed by fine polishing using diamond suspensions having particle sizes of $6,3,1 \mu \mathrm{m}$. For the EBSD analysis, final polishing was carried out using MasterMet 2 (Buehler, IL, USA) non-crystallizing colloidal silica suspension of $0.02 \mu \mathrm{m}$.

Residual stress measurements were performed at EDDI beamline, ${ }^{[21]}$ synchrotron BESSY II (Helmholtz Zentrum Berlin, Germany). This beamline operates in energy dispersive mode and provides a white beam with an energy range of about 10 to $150 \mathrm{keV}$. The $\sin ^{2} \psi$ method in the reflection set-up was used for RS analysis in the subsurface region (around $90 \mu \mathrm{m}$ ). The diffraction angle $2 \theta=10 \mathrm{deg}$ was chosen for all experiments. The prismatic gauge volume was defined by the intersection of the incoming beam (with vertical and horizontal openings $H_{\mathrm{s}}=H_{\mathrm{h}}=1 \mathrm{~mm}$ ) and the diffracted beam (the secondary slits had a vertical opening of $H_{\mathrm{d}}=30$ $\mu \mathrm{m}$, see Figure 2(a)). The resulting gauge volume length 
was $L_{\mathrm{GV}}=5.9 \mathrm{~mm}$. The immersion depth $H_{\mathrm{GV}}$ is defined by slits opening and gauge volume configuration. However, the actually probed region (the so-called information depth) is usually smaller. In order to calculate it, the exponential beam attenuation and the geometrical shape of gauge volume need to be taken into account. $^{[23]}$

Measurements were performed on the top and lateral surfaces. A half map (Figure 2(b)) of the top surface for AB samples and a full map for RE were carried out. The lateral surface was measured only in B-RE due to the small thickness of S-RE sample. As an example, the longitudinal and transversal components were measured

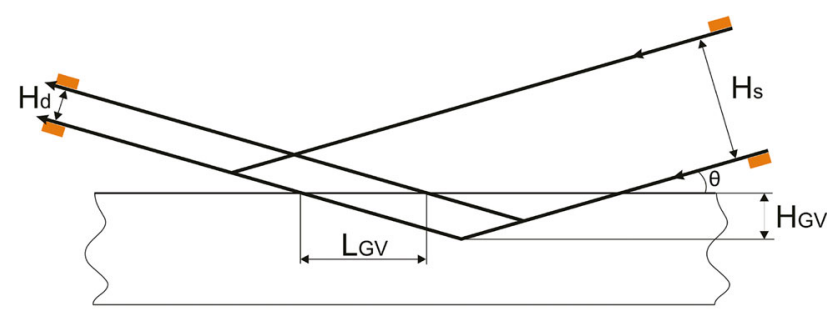

(a)

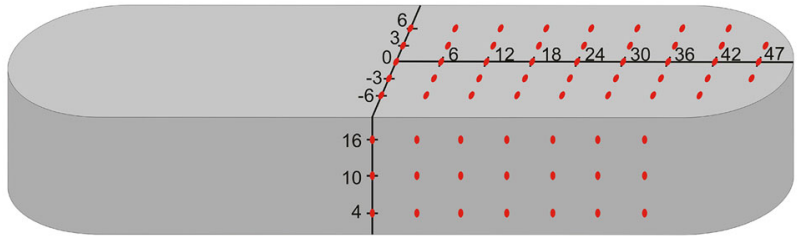

(b)

Fig. 2-(a) Schematic gauge volume; $(b)$ schematic representation of the sample with mapping points.

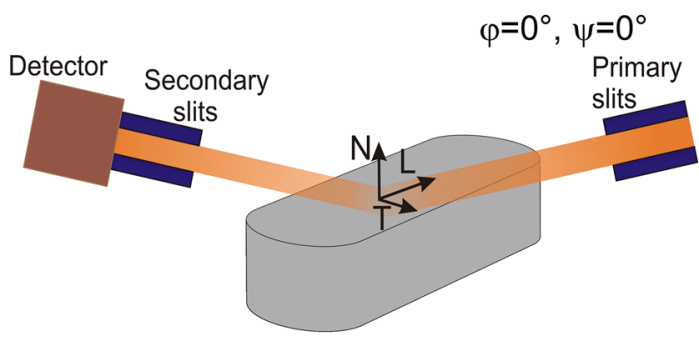

(a)

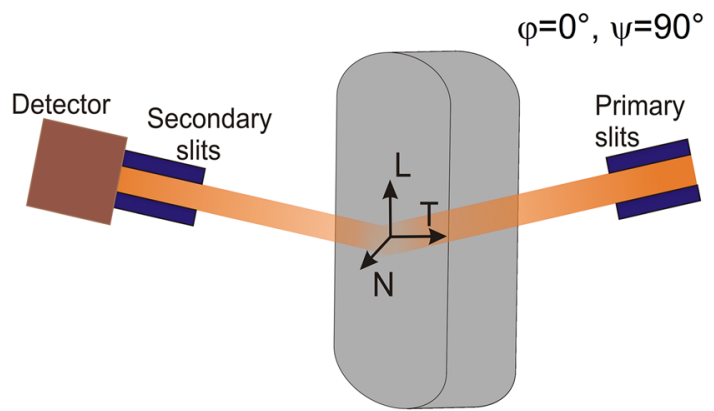

(c) by rotating the sample at two $\varphi$ positions $(\varphi=0 \mathrm{deg}$ for longitudinal and $\varphi=90 \mathrm{deg}$ for transversal, see Figure 3). Since measurements were performed in reflection mode, the stress component orthogonal to the sample surface was assumed to be zero ( $\mathrm{N}$ for the top surface and $\mathrm{T}$ for the lateral surface). Therefore, the absolute values of RS for the transversal and longitudinal components could only be obtained by using a strain-free lattice parameter $d_{0}^{\mathrm{hkl}}$. This parameter was obtained by $d_{\varphi \psi}^{\mathrm{hkl}}-\sin ^{2} \psi$ distributions at the strain-free $\psi^{*}$ value (in the case of a biaxial stress state): $\sin ^{2} \psi^{*}=\frac{-2 S_{1}^{\mathrm{hkl}}}{\frac{1}{2} S_{2}^{\mathrm{hkl}}}$, where $s_{1}^{\mathrm{hkl}}$ and $\frac{1}{2} s_{2}^{\mathrm{hkl}}$ are diffraction elastic constants (DEC), see Reference 24. The $\sin ^{2} \psi$ method yielded the RS in the longitudinal and transversal directions, from the linear fit of $d_{\varphi \psi}^{\mathrm{hkl}} v s \sin ^{2} \psi$ graphs.

The energy dispersive diffraction technique (with the Bragg angle $\theta$ kept constant) allows obtaining the lattice spacing $d^{\text {hkl }}$ for different crystallographic planes $\{\mathrm{hkl}\}$ in dependence of the energy $E_{\mathrm{hkl}}$ :

$$
d^{\mathrm{hkl}}(\AA)=\frac{6.199}{\sin \theta} \frac{1}{E_{\mathrm{hkl}}(\mathrm{keV})} .
$$

The white beam allows probing different depths. ${ }^{[25]}$ In fact, the penetration depth $\tau$ for the energy dispersive diffraction is determined by Reference 21:

$$
\tau=\frac{\sin \theta}{2 \mu\left(E_{\mathrm{hk} 1}\right)} \cos \psi
$$

where $\mu\left(E_{\mathrm{hkl}}\right)$ is the linear absorption coefficient at the $\operatorname{energy} E_{\mathrm{hkl}}$.

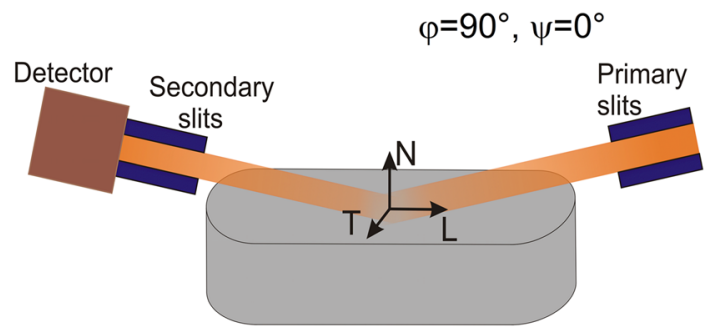

(b)

$$
\varphi=90^{\circ}, \psi=90^{\circ}
$$

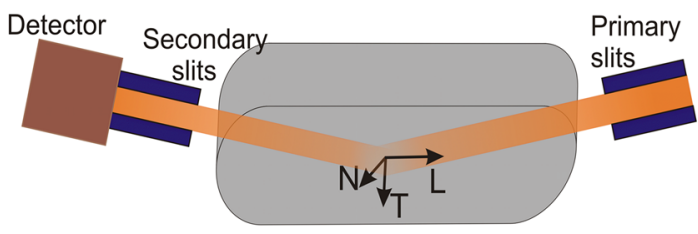

(d)

Fig. 3- Sketch of RS measurement by $\sin ^{2} \psi$ in reflection mode for longitudinal stress component $(a) \psi=0$ deg, $(b) \psi=90$ deg; for transversal stress component $(c) \psi=0 \mathrm{deg},(d) \psi=90 \mathrm{deg}$. 
Additionally assuming that $\mathrm{L}, \mathrm{N}, \mathrm{T}$ are principal stress directions, or in other words that shear stresses vanish, the fundamental equations of X-ray stress analysis for azimuth $\varphi=0 \operatorname{deg}\left(\varepsilon_{0, \psi}\right.$ is L strain component) and $\varphi=90 \mathrm{deg}\left(\varepsilon_{90, \psi}\right.$ is $\mathrm{T}$ strain component $)$ become ${ }^{[24]}$

$$
\begin{gathered}
\varepsilon_{0, \psi}=\frac{1}{2} s_{2} \sigma_{L} \sin ^{2} \psi+s_{1}\left(\sigma_{L}+\sigma_{T}\right) \\
\varepsilon_{90, \psi}=\frac{1}{2} s_{2} \sigma_{T} \sin ^{2} \psi+s_{1}\left(\sigma_{L}+\sigma_{T}\right) .
\end{gathered}
$$

As mentioned before, $\sigma_{\mathrm{T}}$ and $\sigma_{\mathrm{L}}$ could be extracted from a linear fit of $\varepsilon v s \sin ^{2} \psi$. The Von Mises equivalent stresses $\sigma_{\mathrm{vM}}$ were then calculated by

$$
\begin{aligned}
\sigma_{\mathrm{vM}} & =\sqrt{\frac{1}{2}\left[\left(\sigma_{\mathrm{L}}-\sigma_{\mathrm{T}}\right)^{2}+\sigma_{\mathrm{T}}^{2}+\sigma_{\mathrm{L}}^{2}\right]} \\
& =\sqrt{\left[\sigma_{\mathrm{T}}^{2}-\sigma_{\mathrm{L}} \sigma_{\mathrm{T}}+\sigma_{\mathrm{L}}^{2}\right]} .
\end{aligned}
$$

For the calculation of stresses, lattice plane-specific DEC (example for several planes in Table I) were calculated according to the Eshelby/Kröner model. ${ }^{[26,27]}$ DEC $S_{1}$ and $S_{2}$ are connected with elastic constants by the following equations:

$$
\begin{gathered}
s_{1}^{\mathrm{hkl}}=-\frac{v^{\mathrm{hkl}}}{E^{\mathrm{hkl}}} \\
\frac{1}{2} s_{2}^{\mathrm{hkl}}=\frac{1+v^{\mathrm{hkl}}}{E^{\mathrm{hkl}}},
\end{gathered}
$$

where $v^{\mathrm{hkl}}$ and $E^{\mathrm{hkl}}$ are the plane-specific Poisson's ratio and Young's modulus, respectively.

\section{RESULTS}

Optical micrographs representing the regions closer to the top surface of the B sample are shown in Figure 4(a). Up-skin layers were applied during fabrication on the top surface of samples, which is evident from the different effect of the etching procedure observed in the top few layers (Figure 4(a)). The objective of incorporating the up-skin feature during fabrication is to reduce the surface roughness caused by SLM. EBSD-generated orientation maps representing the sample BD for B and S sample are shown in Figures 4(b) and (c), respectively.

Table I. The DEC for Several Crystallographic Planes of $\mathrm{Ni}$

\begin{tabular}{ccc}
\hline $\mathrm{hkl}$ & $s_{1}, \mathrm{MPa}^{-1} \times 10^{-6}$ & $1 / 2 s_{2}, \mathrm{MPa}^{-1} \times 10^{-6}$ \\
\hline 111 & -1.03 & 4.90 \\
200 & -1.90 & 7.53 \\
220 & -1.25 & 5.55 \\
311 & -1.49 & 6.29 \\
511 & -1.37 & 5.94 \\
\hline
\end{tabular}

For the particular scan strategy utilized in this study, columnar-shaped grains with preferred texture $(\langle 001\rangle)$ could be observed in the core structure of both samples irrespective of the support. The contact region of $\mathrm{S}$ sample with the support structure is shown in Figure 4(c). It can be noted that the contact area is small. This is also leading to the formation of some randomly oriented grains in the regions closer to the contact.

The typical diffractogram obtained from synchrotron $\mathrm{X}$-ray diffraction with indexed diffraction peaks is presented in Figure 5(a). The diffraction peaks from ten crystallographic planes could be observed. The lattice strain $\varepsilon_{\mathrm{hkl}}$ vs $\sin ^{2} \psi$ graphs (Figure 5(b)) for transversal component of B-AB sample at the point $L=0 \mathrm{~mm}$, $T=30 \mathrm{~mm}$ show a linear behavior. This behavior is observed for all measurements. Incidentally, we notice that the linearity of the $\varepsilon_{311}$ vs $\sin ^{2} \psi$ graphs and the absence of $\psi$-splitting justify the hypothesis made above of vanishing shear stresses; furthermore, it shows that the texture caused by columnar grain growth (Figure 4(b)) does not impact the validity of our stress analysis. The depth-dependent residual stress profiles from the top surface of the B-AB sample and from the lateral surface of the B-RE sample are shown in Figures 5(c) and (d), respectively. The dashed lines show linear fits of the data.

For the top surface, no gradient in depth was found for any of the samples. The mean value of the depth profile stays around $+600 \mathrm{MPa}$ for transversal and around $-150 \mathrm{MPa}$ for the longitudinal component. In the case of the lateral surface, an increase of stresses as a function of depth was observed for the normal component (from $+500 \mathrm{MPa}$ on surface to almost +1000 $\mathrm{MPa}$ at around $90 \mu \mathrm{m})$.

For the analysis of RS maps, the crystallographic plane $\{311\}$ was chosen as the most weakly influenced by intergranular stresses. ${ }^{[28]}$ The use of this crystallographic plane yields information from a depth around $30 \mu \mathrm{m}$.

Figure 6 reports the residual stress maps of top surface for the transversal stress component. The average error for all maps is around $\pm 40 \mathrm{MPa}$. Samples in $\mathrm{AB}$ condition show an increase of stress toward tip region. In the case of $\mathrm{B}-\mathrm{AB}$, the maximum value is around $+1000 \mathrm{MPa}$, while the thin sample S-AB present the lower values. High tensile stresses, with the maximum around $+850 \mathrm{MPa}$ are confined to the tip region for $\mathrm{S}-\mathrm{AB}$. The area from $L=0$ to $L=30 \mathrm{~mm}$ shows homogeneous stress values, and around +700 $\mathrm{MPa}$ for both specimens. Therefore, the stress gradient along the length (HD) is more pronounced for B-AB.

The removal from the base plate does not significantly change the RS values for $\mathrm{B}-\mathrm{RE}$ in comparison to $\mathrm{B}-\mathrm{AB}$, except the symmetric relaxation of around $100 \mathrm{MPa}$ near the tip. For the thin sample S-RE, the stress gradient remains similar to $\mathrm{S}-\mathrm{AB}$, but the overall stress values decrease by about $200 \mathrm{MPa}$.

The RS mapping of longitudinal stress component is shown in Figure 7. The B-AB sample shows higher stress values (above $+700 \mathrm{MPa}$, Figure 6(b)) in comparison to $\mathrm{S}-\mathrm{AB}$ (where the maximum is +550 $\mathrm{MPa})$. Also, the stress gradient along the length (HD) is 

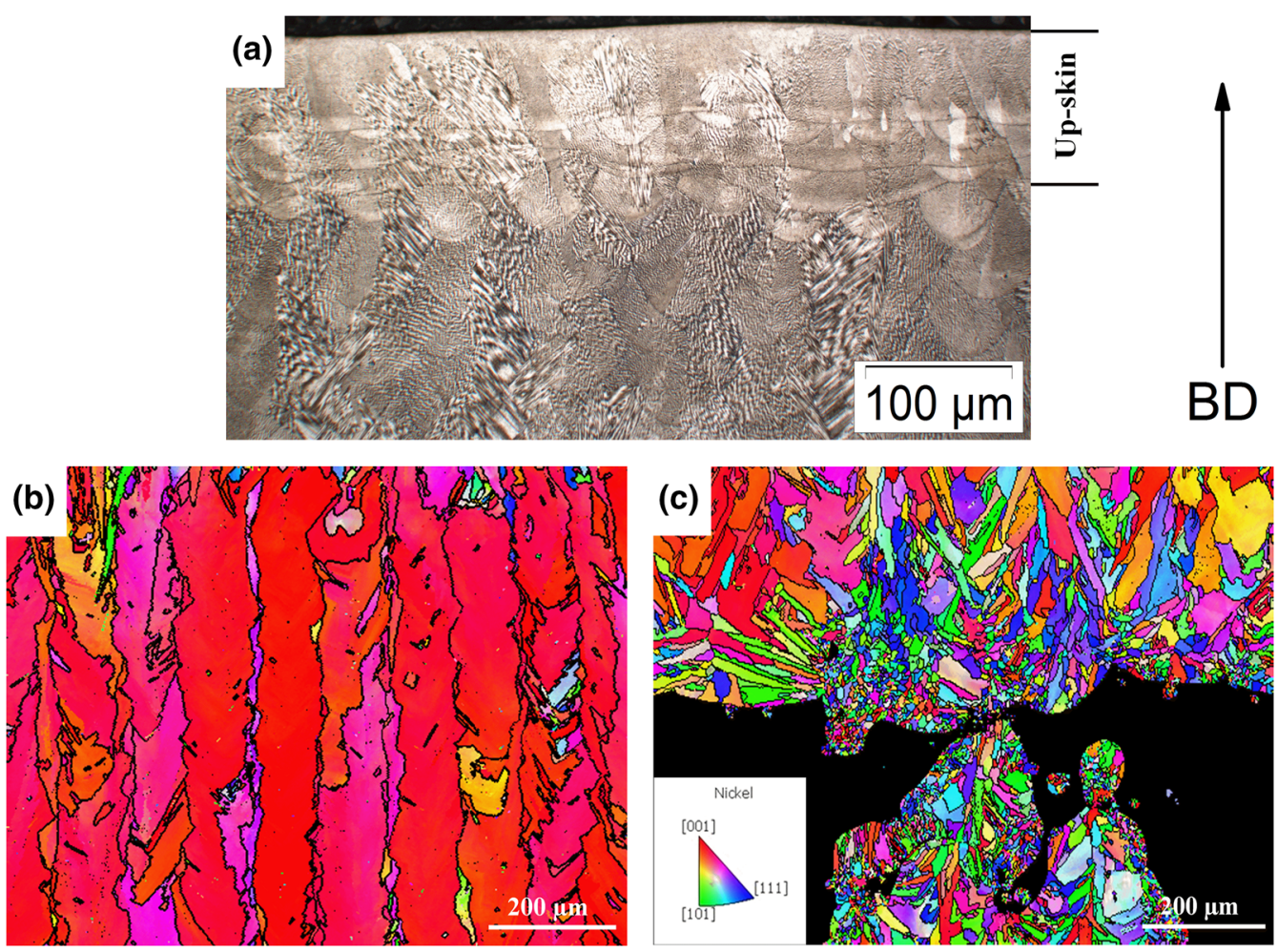

Fig. 4 - (a) Optical micrographs representative of the top layers of B samples; Inverse Pole Figure maps $(b)$ in the core structure of B sample, $(c)$ contact regions between the support and $\mathrm{S}$ sample.

larger for B-AB. RS values go from compressive $(-100$ $\mathrm{MPa})$ in the middle of sample $(L=0 \mathrm{~mm})$ to high tensile at the tip $(+700 \mathrm{MPa})$. The $\mathrm{S}-\mathrm{AB}$ sample shows a similar stress gradient, going from $0 \mathrm{MPa}$ to around + $600 \mathrm{MPa}$.

The gradient along the length (HD) decreases for both samples after removal from the base plate. A stress relaxation can be observed for B-RE: in the middle of sample stresses go from -100 to $0 \mathrm{MPa}$, and near tip they go from +700 to $+550 \mathrm{MPa}$. The sample on support S-RE (Figure 7(d)) shows an overall decrease of stress values (redistribution); this leads to a stress gradient similar to that in $\mathrm{AB}$ condition (see Figure 7(b) and (d)).

Figure 8 shows the residual stress maps of lateral surface of sample B-RE. The normal component (along $\mathrm{BD}$, see Figure 1) presents a RS gradient along the height of sample from low tensile values at the bottom $(+500 \mathrm{MPa})$ to higher tensile near the top $(+800$ $\mathrm{MPa})$. At the same time, the longitudinal component (Figure 8(b)) is vanishing nearly everywhere, except at two symmetric points close to the tip at both top and bottom surfaces.

Figure 9 shows the distortion maps of the top surface for both samples obtained by CMM. The difference between the conditions $\mathrm{AB}$ and RE (Figure 9(c), (f)) characterizes the distortion of the samples due to removal from the baseplate. In the case of B sample, only the tip region (from $40 \mathrm{~mm}$ ) shows a significant decrease in height after releasing, while the rest of the sample looks undistorted. For the $\mathrm{S}$ sample, some stripe-like distortion with small amplitude
$(\Delta z=-4 \mu \mathrm{m})$ can be seen in the middle of sample. The difference maps for sample $\mathrm{S}$ show some effect of the removal from the baseplate only at the tip, where the sample bends downwards. The tip region shows a larger distorted area in comparison to the bulk sample. The stripes (in the difference maps of Figure 9(f)) are correlated to the period of the support structure.

\section{DISCUSSION}

The depth-dependent RS profiles (Figure 5(c), (d)) show the absence of the stress gradients from the top surface, while in the case of the lateral surface some gradient can be observed. This effect is based on two factors: thermal input during production and surface roughness. During SLM, every hatch can be viewed as a "heat treatment" for the previous hatches. Since hatches near the surface have less constraints from the surrounding material, the stress relief is more efficient. Therefore, lower stress values are observed closer to surface. The increase of RS in depth from free surface has been assessed experimentally in References 13, 17, and 29 and also predicted numerically. ${ }^{[7]}$ During deposition of up-skin layers, the top surface is remolten with reduced scanning speed, so that a smoother surface can be achieved. The lateral surfaces can present some partially unmolten particles, ${ }^{[29]}$ which are almost stress free, and further lower the average RS at the very surface.

According to the microstructure analysis, the up-skin has a depth of around $140 \mu \mathrm{m}$ (Figure 4), while the 


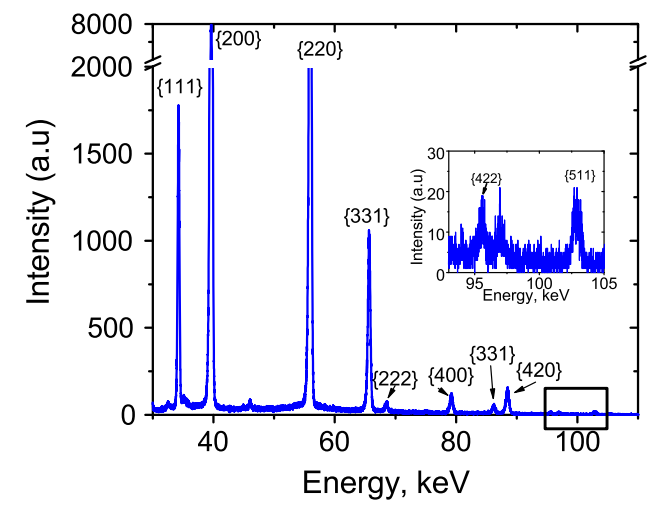

(a)

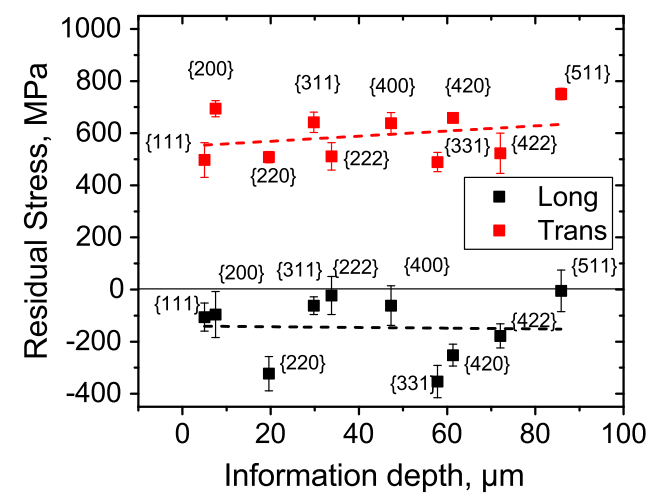

(c)

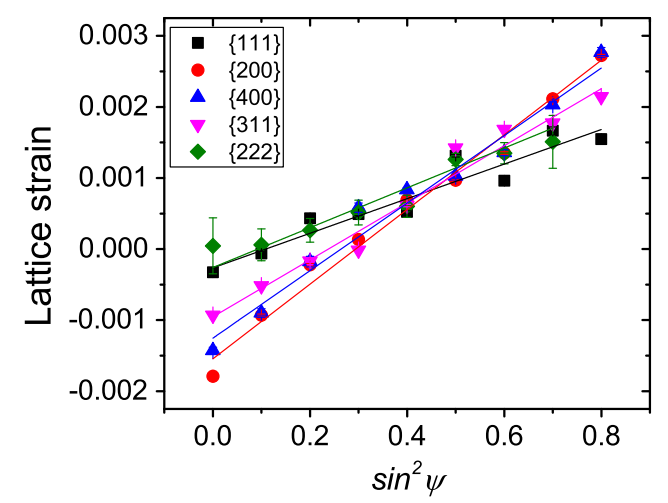

(b)

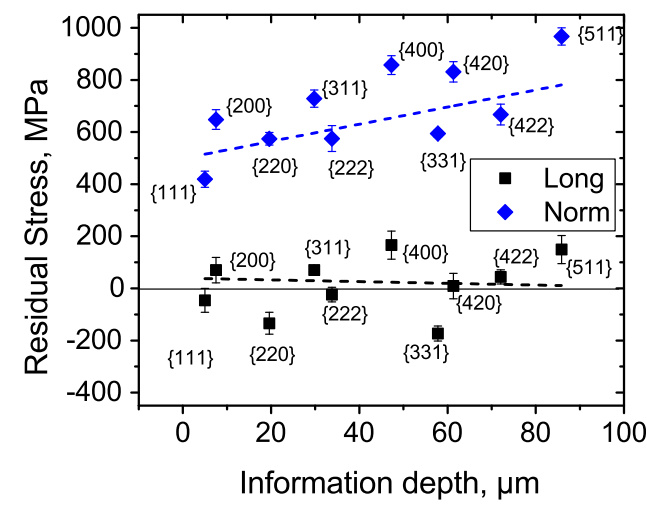

(d)

Fig. 5- (a) Typical diffractogram with labeled diffraction peaks, (b) linear fitting of $\sin ^{2} \psi$ plots for samples B-AB, $(c)$ the RS penetration depth profile $\mathrm{B}-\mathrm{AB}$ on the top surface (note that sample $\mathrm{S}$ also shows no stress gradient in depth), (d) the RS penetration depth profile B-RE on the lateral surface.
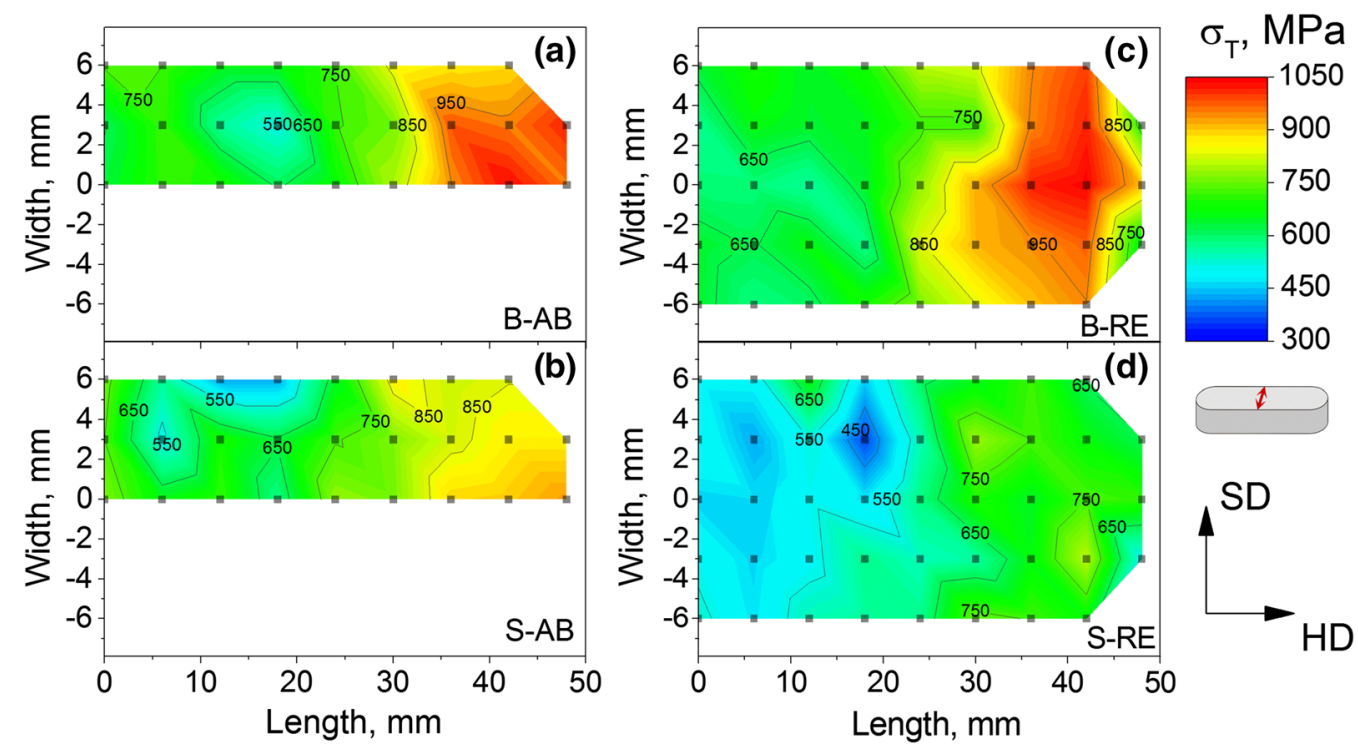

Fig. 6- Residual stress maps of the transversal component of the top surface $(a) \mathrm{B}-\mathrm{AB},(b) \mathrm{S}-\mathrm{AB},(c) \mathrm{B}-\mathrm{RE},(d) \mathrm{S}-\mathrm{RE}$. The average error is \pm 40 MPa.

maximum information depth obtained during the diffraction experiment for crystallographic plane $\{511\}$ is around $90 \mu \mathrm{m}$ (Figure 5). Therefore, only up-skin layers could be characterized. Nevertheless, in spite of the fact that both $\mathrm{S}$ and B samples had the same up-skin processing, strongly different RS maps were found. This fact highlights the strong dependence of RS from scanning parameters and sample geometry. 

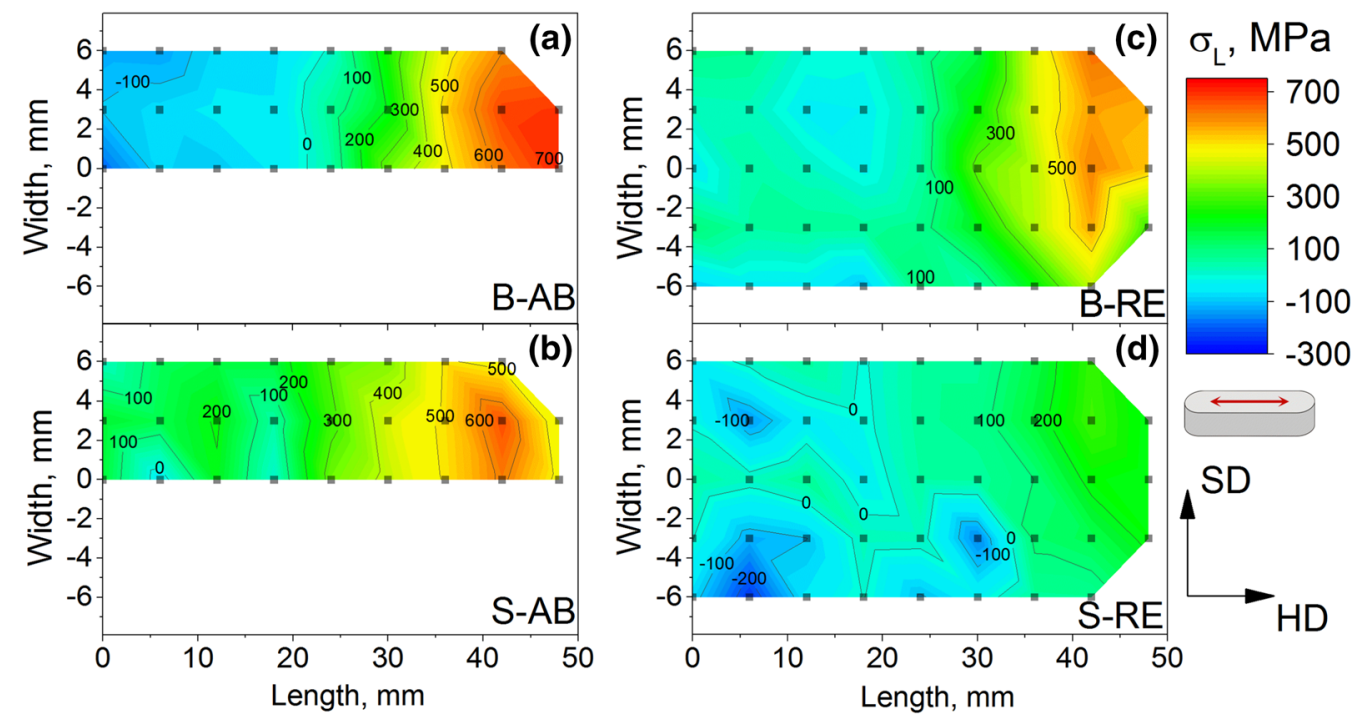

Fig. 7- Residual stress maps of the longitudinal component of the top surface (a) B-AB, (b) S-AB, (c) B-RE, (d) S-RE. The average error is \pm $40 \mathrm{MPa}$. Note the different scales than Fig. 6.
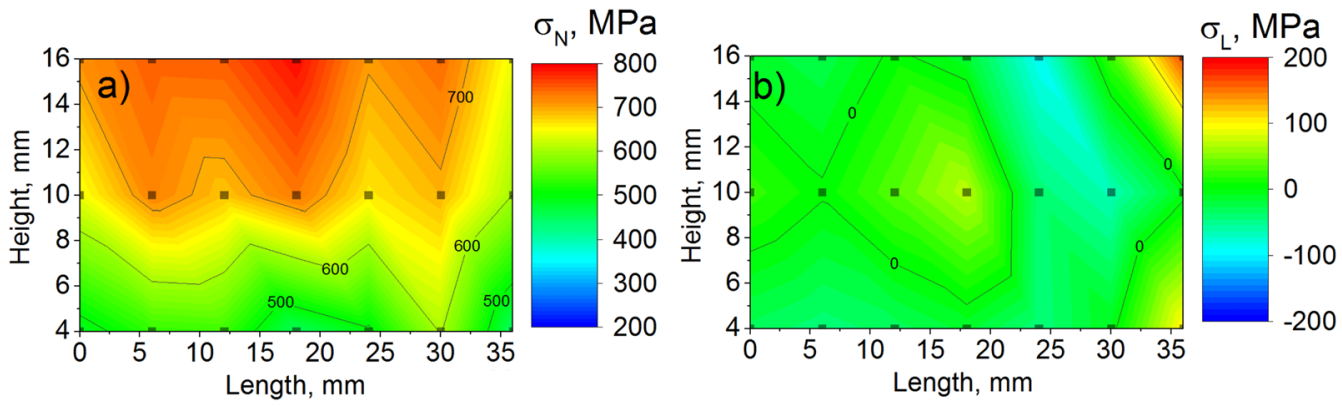

Fig. 8- Residual stress maps of $(a)$ normal component and $(b)$ longitudinal component in B-RE sample. The average error is $\pm 40 \mathrm{MPa}$.

No stress gradient on lateral surface (Figure 8) for the longitudinal component was found, since the hatch length is almost equal to the length of the sample, and the laser energy input is more homogeneous along the length. The decrease of stresses on the lateral surface from top to the bottom can be explained by a partial stress relief due to remelting of cooled lower layers during deposition of upper layers. Also, this stress gradient can be explained by removal from the base plate. The free bottom surface allows releasing stresses, which were previously constrained by the base plate. Indeed, some studies show that the connection between part and base plate contribute to the residual stress state. $^{[5,30-32]}$

In general, the scanning parameters during SLM have a significant influence on residual stress state, due to changes in the heat input and thermal gradient: The scanning strategy with smaller hatch length in similar IN718 SLM samples ${ }^{[20,33]}$ has shown the highest gradient in longitudinal and transversal directions in comparison with longer hatch, because of more localized laser energy input; the increase of the laser energy density by means of smaller scanning speed has shown to decrease residual stresses. ${ }^{[17]}$ In the present case, the support structure can also be viewed as a process parameter since its shape and size can be changed depending on the component and its purpose. For the comparison between the two samples with and without support structure, the equivalent von Mises stresses (Figure 10) on the top surface were calculated according to Eq. [5].

The sample with support structure clearly shows a lower level of von Mises stress in both (AB and RE) conditions in comparison to the bulk sample. This was also seen for the longitudinal and the transversal components separately (Figures 6 and 7). On top surface of $\mathrm{B}-\mathrm{AB}$ von Mises stress values with a maximum of $+1000 \mathrm{MPa}$ were found; this value is near the yield stress of SLM IN718 reported in Reference 34. The lower temperature gradient during scanning for $\mathrm{S}$ sample, and thereby lower RS, may be caused not only by the presence of the support structure but also by the smaller number of layers. ${ }^{[8]}$ Also, it could be connected with the relaxation of the transversal component for S-RE sample due to removal from the base plate. The sample S-RE presents a large distorted area near the tip than B-RE (Figure 8(c), (f)). The smaller thickness of the sample and the small area of contact with the support structure (Figure 4) give more compliance to this sample. At the same time, B-RE shows a symmetric 


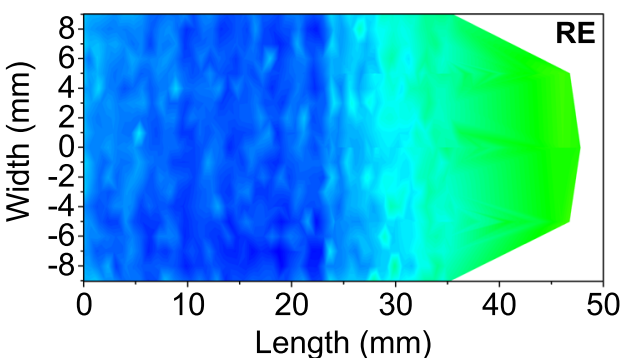

(a)

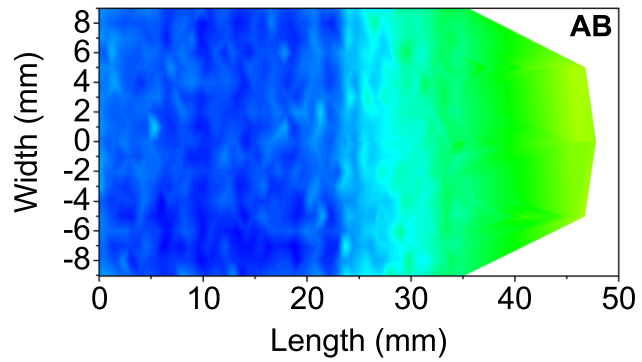

(b)

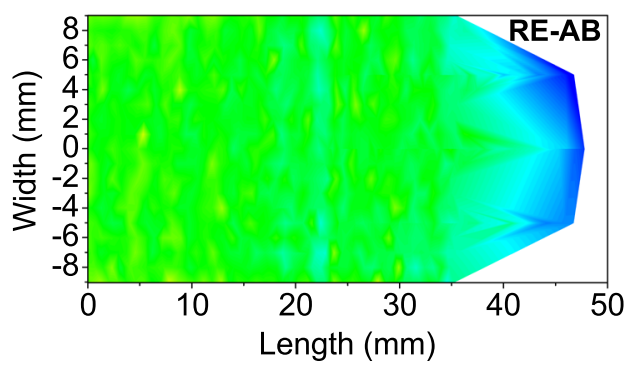

(c)

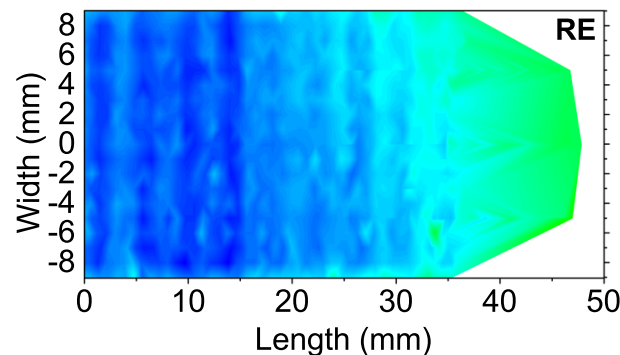

(d)

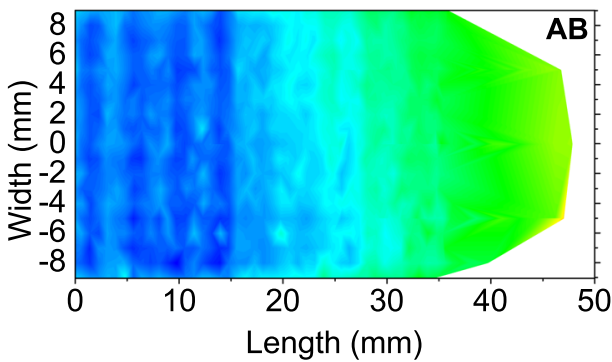

(e)

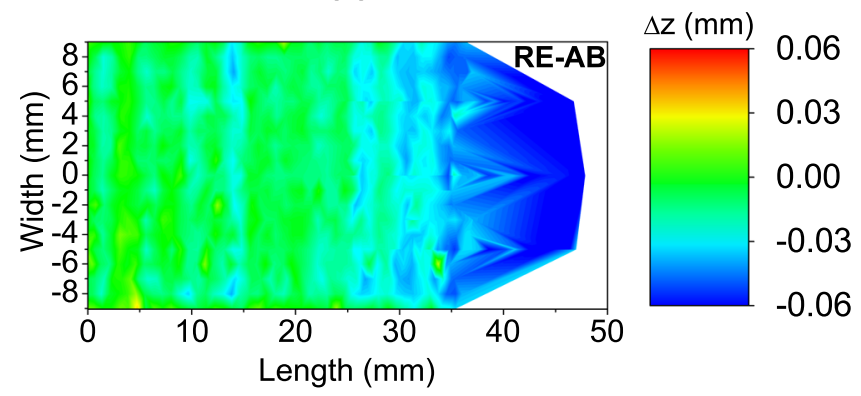

(f)

Fig. 9- Distortion measurements by CMM for B $(a) \mathrm{AB},(b) \mathrm{RE},(c)$ the difference RE-AB; for $\mathrm{S}(d) \mathrm{AB},(e)$ RE, $(f)$ the difference RE-AB.
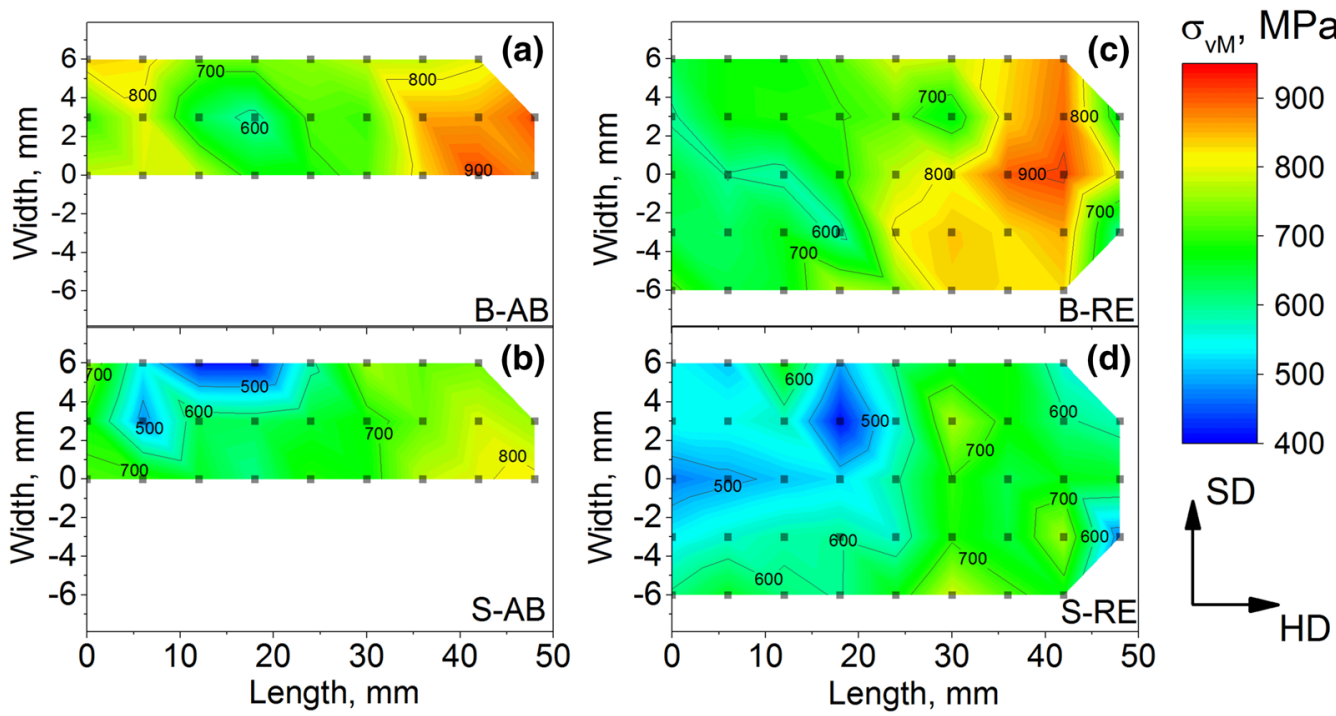

Fig. 10- Von Mises stresses (a) B-AB, (b) S-AB, (c) B-RE, (d) S-RE.

(with respect to the middle line near tip region, Figure 6(c)) stress relaxation pattern after removal from the base plate, as shown by the distortion maps shown in Figure 9(c). As also discussed in Reference 8, the longitudinal stress component has lower values compared to the transversal. The longitudinal component shows stress relaxation for sample B and stress redistribution for sample $\mathrm{S}$, after removal from the base plate. 
This fits with the fact that distortion gradients along HD are much larger than those along SD (Figure 9). However, even for the sample with support structure, the RS reaches $+700 \mathrm{MPa}$. We can conclude that even by using support structures, stress-relieving heat treatment after production cannot be avoided and should be tailored for every component. Especially, considering the high distortion when the part is being removed from the base plate or from the supports, an upfront stress relief seems to be mandatory.

\section{CONCLUDING REMARKS}

SLM IN718 prisms, both on a support structure and bulk, show the presence on high tensile residual stresses in subsurface region in both the as-built condition and after removal from the base plate. Stress gradients were found along the hatching direction for the two in-plane principal stress components within the top surface. The transversal stress component (i.e., along the scanning direction) proved to be the largest. The removal from the base plate affects residual stresses in form of stress redistribution for the sample on supports, and of stress relaxation for the bulk sample, especially in the hatching direction. The support structure gives more compliance to the sample and results in higher distortion, with stripe-like pattern correlated with period of the support structure. Although the sample on support structure showed lower stress values in comparison to the bulk one, heat treatments after production need still to be performed if one wants to reduce the amount of residual stress and prevent large distortion when separating the part.

\section{REFERENCES}

1. C.Y. Yap, C.K. Chua, Z.L. Dong, Z.H. Liu, D.Q. Zhang, L.E. Loh, and S.L. Sing: Appl. Phys. Rev., 2015, vol. 2, p. 041101.

2. L.E. Murr, S.M. Gaytan, D.A. Ramirez, E. Martinez, J. Hernandez, K.N. Amato, P.W. Shindo, F.R. Medina, and R.B. Wicker: J. Mater. Sci. Technol., 2012, vol. 28, pp. 1-14.

3. B.P. Conner, G.P. Manogharan, A.N. Martof, L.M. Rodomsky, C.M. Rodomsky, D.C. Jordan, and J.W. Limperos: Addit. Manuf., 2014, vols. $1-4$, pp. 64-76.

4. A.E. Patterson, S.L. Messimer, and P.A. Farrington: Technologies, 2017, vol. 5 , p. 15.

5. J.P. Kruth, J. Deckers, E. Yasa, and R. Wauthle: Proc. Inst. Mech. Eng. Part B: J. Eng. Manuf., 2012, vol. 226, pp. 980-91.
6. I. Yadroitsev and I. Yadroitsava: Virtual Phys. Prototyp., 2015, vol. 10, pp. 67-76.

7. G. Vastola, G. Zhang, Q.X. Pei, and Y.W. Zhang: Addit. Manuf., 2016, vol. 12, pp. 231-39.

8. P. Mercelis and J.P. Kruth : Rapid Prototyp. J., 2006, vol. 12, pp. 254-65.

9. M.F. Zaeh and G. Branner : Prod. Eng., 2009, vol. 4, pp. 35-45.

10. Y. Liu, Y. Yang, and D. Wang : Int. J. Adv. Manuf. Technol., 2016, vol. 87, pp. 647-56.

11. B. Cheng, S. Shrestha, and K. Chou : Addit. Manuf., 2016, vol. 12, pp. 240-51.

12. I. van Zyl, I. Yadroitsava, and I. Yadroitsev: S. Afr. J. Ind. Eng., 2016, vol. 27, pp. 134-41.

13. A. Salmi, E. Atzeni, L. Iuliano, and M. Galati: Procedia CIRP, 2017, vol. 62, pp. 458-63.

14. F. Calignano: Mater. Des., 2014, vol. 64, pp. 203-13.

15. K. Zeng, D. Pal, C. Teng, and B.E. Stucker : Addit. Manuf., 2015, vol. 6 , pp. 67-73.

16. A.S. Wu, D.W. Brown, M. Kumar, G. Gallegos, and W.E. King : Metall. Mater. Trans. A, 2014, vol. 45, pp. 6260-70.

17. T. Mishurova, S. Cabeza, K. Artzt, J. Haubrich, M. Klaus, C. Genzel, G. Requena, and G. Bruno: Materials, 2017, vol. 10, pp. $348-62$.

18. B. Vrancken, R. Wauthlé, J.-P. Kruth, J. van Humbeeck: Proceedings Solid Freeform Fabrication Symposium, Austin, TX, USA, 2013, pp 1-15.

19. L.M. Sochalski-Kolbus, E.A. Payzant, P.A. Cornwell, T.R. Watkins, S.S. Babu, R.R. Dehoff, M. Lorenz, O. Ovchinnikova, and C. Duty: Metall. Mater. Trans. A, 2015, vol. 46, pp. 1419-32.

20. T. Thiede, S. Cabeza, T. Mishurova, N. Nadammal, A. Kromm, J. Bode, C. Haberland, and G. Bruno: Mater. Perform. Charact., 2018 (in press).

21. C. Genzel, I.A. Denks, J. Gibmeier, M. Klaus, and G. Wagener: Nucl. Instrum. Methods Phys. Res. Sect. A: Accel. Spectrom. Detect. Assoc. Equip., 2007, vol. 578, pp. 23-33.

22. C.-Y. Fang, C. K. Sung, K.-W. Lui: ASPE Proceedings, Norfolk, VA, USA, 2005

23. M. Meixner, M. Klaus, and C. Genzel: J. Appl. Crystallogr., 2013, vol. 46, pp. 610-18.

24. V. Hauk : Structural and Residual Stress Analysis by Nondestructive Methods, Elsevier Science B.V, Amsterdam, 1997

25. B.C. Giessen G.E. Ordon : Science, 1968, vol. 159, pp. 973-75.

26. J.D. Eshelby: Proc. R. Soc. Lond. Ser. A. Math. Phys. Sci., 1957, vol. 241 , pp. $376-96$.

27. E. Kröner: Z. für Phys., 1958, vol. 151, pp. 504-18.

28. T.M. Holden, A.P. Clarke, and R.A. Holt: Met. Trans., 1997, vol. 28A, pp. 2565-76.

29. T. Simson, A. Emmel, A. Dwars, and J. Böhm: Addit. Manuf., 2017, vol. 17, pp. 183-89.

30. B.A. Szost, S. Terzi, F. Martina, D. Boisselier, A. Prytuliak, T. Pirling, M. Hofmann, and D.J. Jarvis: Mater. Des., 2016, vol. 89, pp. 559-67.

31. T. Mukherjee, W. Zhang, and T. DebRoy: Comput. Mater. Sci., 2017, vol. 126, pp. 360-72.

32. C.A. Brice and W.H. Hofmeister: Metall. Mater. Trans. A, 2013, vol. 44 , pp. $5147-53$.

33. N. Nadammal, S. Cabeza, T. Mishurova, T. Thiede, A. Kromm, C. Seyfert, L. Farahbod, C. Haberland, J.A. Schneider, P.D. Portella, and G. Bruno: Mater. Des., 2017, vol. 134, pp. 139-50.

34. C. Seyfert, Technical University Berlin, Master Thesis, (German, restricted to Siemens AG), 2016. 